\title{
Land Fragmentation in Bulgaria: Reconsidering Its Measurement and Extent
}

\author{
Natalia Boliari ${ }^{1}$ \\ ${ }^{1}$ School of Business, Manhattan College, New York, USA \\ Correspondence: Natalia Boliari, School of Business, Manhattan College, Riverdale, NY 10471, USA. Tel: \\ 1-718-862-3858. E-mail: natalia.boliari@manhattan.edu
}

Received: November 20, 2012 Accepted: January 15, 2013 Online Published: February 21, 2013

doi:10.5539/res.v5n1p99

URL: http://dx.doi.org/10.5539/res.v5n1p99

\begin{abstract}
This study investigates the extent of land fragmentation in Bulgaria, where it is considered a major agricultural and land reform issue. Using data from the Bulgaria 2003 Multitopic Household Survey as well as other data sets pertaining to late 19th and early 20th century, the paper shows that the current level of land fragmentation is low-to-moderate in Bulgaria and that fragmentation is at its lowest level in about a century. This finding is in contrast to some of the existing research which has suffered from measurement problems. The paper underlines the significance of differentiating between land fragmentation and farm size to reveal an accurate portrayal of the extent of land use.
\end{abstract}

Keywords: Bulgaria, agriculture, land fragmentation, Simmons Index, undersized farms

\section{Introduction}

Land fragmentation (LF), commonly defined as the situation where a farm is composed of more than one separate plot of land, has been identified as a major undesirable outcome of the 1991 Bulgarian land reform initiated at the outset of the transition from a centrally planned to a market economy. ${ }^{1}$ A review of the literature and government documents discussing the problems in Bulgarian agriculture reveals that all point to LF as one of the major obstacles to the productive and efficient use of land and other agricultural resources; to the development of efficient land markets, private and public investments; and therefore to sustainable economic growth and social development. ${ }^{2}$ In response to the perceived disadvantages of LF, the Bulgarian Ministry of Agriculture and Food Supply (MAFS) initiated a number of projects to assess farmers' willingness to consolidate their land and to develop policies for farm land consolidation (MAFS 2004, p. 22-27). The pre-communist (pre-1944) level of fragmentation, which was estimated to be in the range of ten to 15 parcels per farm based on agricultural census data, was thought to be too high. The post-communist era of fragmentation is believed to be as alarming as the one that existed in the pre-communist era, although there is a surprisingly large degree of disparity in the reported average number of parcels, with a range from two to 11 (See Note 1).

Using the Bulgaria 2003 Multitopic Household Survey data and employing the Simmons Index (SI) to measure LF, this study demonstrates that fragmentation in Bulgaria is significantly lower than most of the estimates reported in the literature. Furthermore, comparing the LF estimates obtained from the 2003 data to those obtained from the agricultural census data sets of 1897, 1908, 1926, and 1934 reveals that there has been a dramatic decline in fragmentation in the post-communist period. This finding is in sharp contrast to the widely-held but not empirically supported belief that LF levels have risen considerably following the land reform of 1991.

The paper underlines the importance of distinguishing the phenomenon of LF from the related but separate issue of land subdivision and farm size. Put differently, this paper focuses on the proper definition and measurement of LF. It demonstrates the pitfalls of using the incorrect measures and misleading inferences that can be generated by these measures. Specifically, the misconception about the extent of LF seems to arise because the measurement of LF is confounded with the phenomenon of small landownership and undersized farms. Correcting this misconception is critical for the precise determination of the nature and causes of fragmentation; for the development of appropriate methodology to test its impact on land productivity and other economic 
outcomes; and ultimately, for the design and implementation of policies targeting correctly the areas which require policy intervention.

The paper is organized as follows: Section 2 presents a brief overview of the measures of LF; Section 3 presents and analyzes the historical level of LF in Bulgaria along with reviewing estimates relating to both the pre- and post- communist periods; Section 4 analyzes the survey data and discusses the results relating to the 2003 level of LF; and Section 5 concludes.

\section{An Overview of the Measures of Land Fragmentation}

Land fragmentation is most often defined as "the type of land ownership pattern where a single farm consists of numerous discrete parcels [plots], often scattered over a wide area" (Bentley, 1987). In line with this definition, a farm can be described as consolidated when it is composed of just one plot of land; a fragmented farm, on the other hand, is a farm which consists of more than one plot (Simmons, 1964).

The problem is, as King and Burton (1982) indicate, that fragmentation "is often taken to imply the subdivision of farm property into undersized units which are too small for rational exploitation." Such a conceptualization of fragmentation creates confusion by failing to differentiate the issue of having small-sized farms or small-sized plots from the issue of having farms composed of several plots, regardless of their size. As suggested by King and Burton, the issue of undersized farms is conceptually and practically different from the issue of fragmented farms. Therefore, these two should be studied and analyzed separately.

A major problem in relation to studying or assessing LF is the lack of a consensus on a standard objective measure of the degree of fragmentation (Bentley, 1987; Blarel et al., 1992; Hung et al., 2007; King \& Burton, 1982). This leads to confusions and difficulties in (1) determining whether or when farms are 'too fragmented'; (2) defining the criteria for the need of consolidation; and (3) comparing LF and its impacts across countries (Bentley, 1987).

Given that fragmentation is defined across a large geographic area such as a province or country and is concerned with the organization of farms in location and space, King and Burton (1982) identify six characteristics of plots as the parameters desirable in assessing the degree of LF: (1) the farm size; (2) the number of plots; (3) the size of plots; (4) the size distribution of plots; (5) the spatial distribution of plots; and (6) the shape characteristics of plots. However, the commonly used fragmentation indices do not incorporate all of these parameters; rather, they measure at most three of these (e.g. the Simmons Index (Simmons, 1964), the Januszewski Index (Januszewski, 1968), the Igbozurike Index (Igbozurike, 1974), and the Simpson Index of Blarel et al. (1992)) (Note 3).

None of the indices listed above are used to measure LF in Bulgaria. Consequently, the discourse on Bulgarian LF has relied on indicators of fragmentation such as the average parcel size or the average number of parcels per farm. In Section 4 of this paper, the extent of LF is calculated using a well established index and data from 2003.

\section{Measuring Land Fragmentation in Bulgaria}

\subsection{Pre-Communist Period}

The discussion of the problems of agriculture in Bulgaria before collectivization of land under the communist regime focuses on two well known major issues: division of land into small parcels and the "emergence" of LF (Berov, 1981, p. 374; Dräger \& Jaksch, 2001, p. 182; Howe, 1998, p. 210; Kopeva, 2000; 2001; Toshev, 1937, p. 20; Vulchev, 1999, p. 139-145). The arguments are mostly based on data from the agricultural censuses conducted in 1897, 1908, 1926, and 1934. Indeed, the figures obtained from these censuses show the prevalence of small farms and parcels as well as the prevalence of farms composed of too many parcels. But they also show that fragmentation does not necessarily lead to small farm size. It actually appears that an increase in farm size is associated with an increase in fragmentation.

Table 1 shows the data on distribution of land in Bulgaria collected during the Bulgarian agricultural censuses of 1897 and 1908; Table 2 displays the same information for 1926 and 1934. From these data, the only way to measure fragmentation is to calculate the national average of parcels per farm, which is exactly what most studies do. To have a better idea about the number of parcels per farm and to further analyze the data, in this study the average number of parcels per farm for each farm size range was calculated along with the percentage change in the number of farms, in the number of parcels, and in average parcels per farm from 1897 to 1908 , from 1908 to 1926, and from 1926 to 1934.

The data show evidence of fragmentation: in 1897 the overall average number of parcels per farm is 10 ; the lowest average is 1.5 parcels for farms below 5 decares (daa) ( 1 daa $\approx 0.25$ acres), and the highest is 38.5 for 
farms in the 3000-5000 daa size range. In 1908 the overall average number of parcels per farm increases to 11 with the lowest subgroup average being 1 parcel for farms smaller than 5 daa and the highest being 46 for farms both in the 2000-3000 and above 5000 daa range. Table 2 shows that in 1926 the overall average number of parcels per farm rises to 15 with the lowest average of 3 parcels per farm for farms of sizes less than 10 daa and the highest average of 37 for farms of sizes greater than 500 daa. In 1934 the overall average number of parcels per farm decreases to 13. Moreover, there is a general decrease, compared to previous years, in the average number of parcels per farm for farms in all size ranges. The lowest average remains 3 for farms as big as or below 10 daa and the highest average drops to 32 for farms larger than 500 daa. The figures support the early findings of Simmons (1964) and Januszewski (1968) that an increase in farm size is accompanied by an increase in fragmentation.

Table 1. Land distribution in Bulgaria in 1897 and 1908

\begin{tabular}{|c|c|c|c|c|c|c|c|c|c|c|c|c|c|c|}
\hline \multirow{2}{*}{$\begin{array}{l}\text { 1. Size } \\
\text { of farms } \\
\text { (in } \\
\text { decares) }\end{array}$} & \multicolumn{2}{|c|}{$\begin{array}{l}\text { Number of farms } \\
\text { (in thousands) }\end{array}$} & \multicolumn{2}{|c|}{ Percent of farms } & \multicolumn{2}{|c|}{$\begin{array}{c}\text { Total decares in each } \\
\text { farm interval listed in } \\
\text { column (1) } \\
\text { (in thousands) }\end{array}$} & \multicolumn{2}{|c|}{ Percent of land } & \multicolumn{2}{|c|}{$\begin{array}{c}\text { Total number of parcels } \\
\text { in each farm interval } \\
\text { listed in column (1) in } \\
\text { thousands }\end{array}$} & \multicolumn{2}{|c|}{$\begin{array}{l}\text { Average parcels per } \\
\text { farm }\end{array}$} & \multicolumn{2}{|c|}{ Percent of parcel } \\
\hline & $\begin{array}{c}2 . \\
1897\end{array}$ & $\begin{array}{c}3 . \\
1908\end{array}$ & $\begin{array}{c}4 . \\
1897\end{array}$ & $\begin{array}{c}5 . \\
1908\end{array}$ & $\begin{array}{l}6 . \\
1897\end{array}$ & $\begin{array}{c}7 . \\
1908\end{array}$ & $\begin{array}{c}8 . \\
1897\end{array}$ & $\begin{array}{c}9 . \\
1908\end{array}$ & $\begin{array}{c}10 . \\
1897\end{array}$ & $\begin{array}{c}11 . \\
1908\end{array}$ & $\begin{array}{c}(10) /(2) \\
1897\end{array}$ & $\begin{array}{c}(11) /(3) \\
1908\end{array}$ & $\begin{array}{c}14 . \\
1897\end{array}$ & $\begin{array}{c}15 . \\
1908\end{array}$ \\
\hline $\begin{array}{l}\text { Less } \\
\text { than } 5\end{array}$ & 166.8 & 180.3 & 21 & 19 & 416.5 & 462.3 & 1 & 1 & 248.1 & 265.6 & 1.5 & 1 & 3 & 3 \\
\hline 5-10 & 90.5 & 113.4 & 11 & 12 & 673 & 837.5 & 1.7 & 1.8 & 247.2 & 285.7 & 2.7 & 3 & 3 & 3 \\
\hline $10-20$ & 106.4 & 131.2 & 13 & 14 & 1567 & 1915.9 & 3.9 & 4.2 & 547.8 & 605.8 & 5.2 & 5 & 7 & 6 \\
\hline $20-30$ & 75.1 & 86.5 & 9 & 9 & 1873 & 2149.5 & 4.7 & 4.6 & 653.5 & 712.3 & 8.7 & 8 & 8 & 7 \\
\hline $30-40$ & 60.1 & 68.4 & 8 & 8 & 2097.4 & 2385.1 & 5.3 & 5.2 & 693.3 & 786.7 & 11.5 & 12 & 9 & 8 \\
\hline $40-50$ & 50.2 & 57.8 & 6 & 6 & 2257.5 & 2595.9 & 5.7 & 5.6 & 684.7 & 821.6 & 13.6 & 14 & 8 & 8 \\
\hline $50-75$ & 92.5 & 106.6 & 12 & 12 & 5700 & 6573.2 & 14.3 & 14.2 & 1491.5 & 1845.8 & 16.1 & 17 & 19 & 19 \\
\hline $75-100$ & 56.5 & 67.5 & 7 & 7 & 4883.2 & 5845 & 12.3 & 12.6 & 1050.8 & 1394.3 & 18.6 & 21 & 13 & 14 \\
\hline $100-150$ & 55.5 & 67.6 & 7 & 7 & 6720.1 & 8186.7 & 16.9 & 17.7 & 1174.4 & 1595.9 & 21.2 & 24 & 15 & 16 \\
\hline $150-200$ & 22.1 & 26.7 & 3 & 3 & 3791.7 & 4583.1 & 9.5 & 9.9 & 525 & 710.9 & 23.8 & 27 & 6 & 7 \\
\hline $200-300$ & 14.9 & 17.3 & 2 & 2 & 3586.6 & 4123.9 & 9 & 8.9 & 394.4 & 507 & 26.5 & 29 & 5 & 5 \\
\hline $300-400$ & 4.3 & 5 & .5 & 1 & 1484.6 & 1715.6 & 3.7 & 3.7 & 124.6 & 163.6 & 28.7 & 33 & 2 & 2 \\
\hline $400-500$ & 1.8 & 1.9 & .22 & .21 & 787.9 & 862 & 2 & 1.9 & 54.4 & 65.2 & 30.7 & 34 & 1 & 1 \\
\hline $500-100$ & & & & & & & & & & & & & & \\
\hline 0 & 2 & 2.2 & .25 & .24 & 1338.9 & 1478.9 & 3.4 & 3.2 & 61.8 & 77.9 & 31 & 35 & 1 & 1 \\
\hline $1000-20$ & & & & & & & & & & & & & & \\
\hline 00 & 0.61 & 0.6 & .08 & .06 & 826 & 797.4 & 2.1 & 1.7 & 19 & 22.5 & 31.4 & 38 & - & .23 \\
\hline $2000-30$ & & & & & & & & & & & & & & \\
\hline 00 & 0.15 & 0.2 & .02 & .02 & 377.8 & 375.4 & 1 & 0.8 & 5.9 & 7 & 38 & 46 & - & .07 \\
\hline $3000-50$ & & & & & & & & & & & & & & \\
\hline 00 & 0.1 & 0.1 & .01 & .01 & 427.4 & 372.9 & 1.1 & 0.8 & 3.6 & 4.5 & 35.8 & 45 & - & .05 \\
\hline $\begin{array}{l}\text { More } \\
\text { than }\end{array}$ & & & & & & & & & & & & & & \\
\hline 5000 & 0.09 & 0.1 & .01 & .01 & 966.4 & 997.6 & 2.4 & 2.2 & 2.4 & 4.2 & 27.7 & 46 & - & .04 \\
\hline Total & 799.7 & 933.4 & 100 & 100 & 39775 & 46257.9 & 100 & 100 & 7982.4 & 9876.5 & 10 & 11 & 100 & 100 \\
\hline
\end{tabular}

Source: Statistical Yearbook of the Kingdom of Bulgaria (1909, p. 183; 1915, p. 128-129) and author's calculations. 
Table 2. Land distribution in Bulgaria in 1926 and 1934

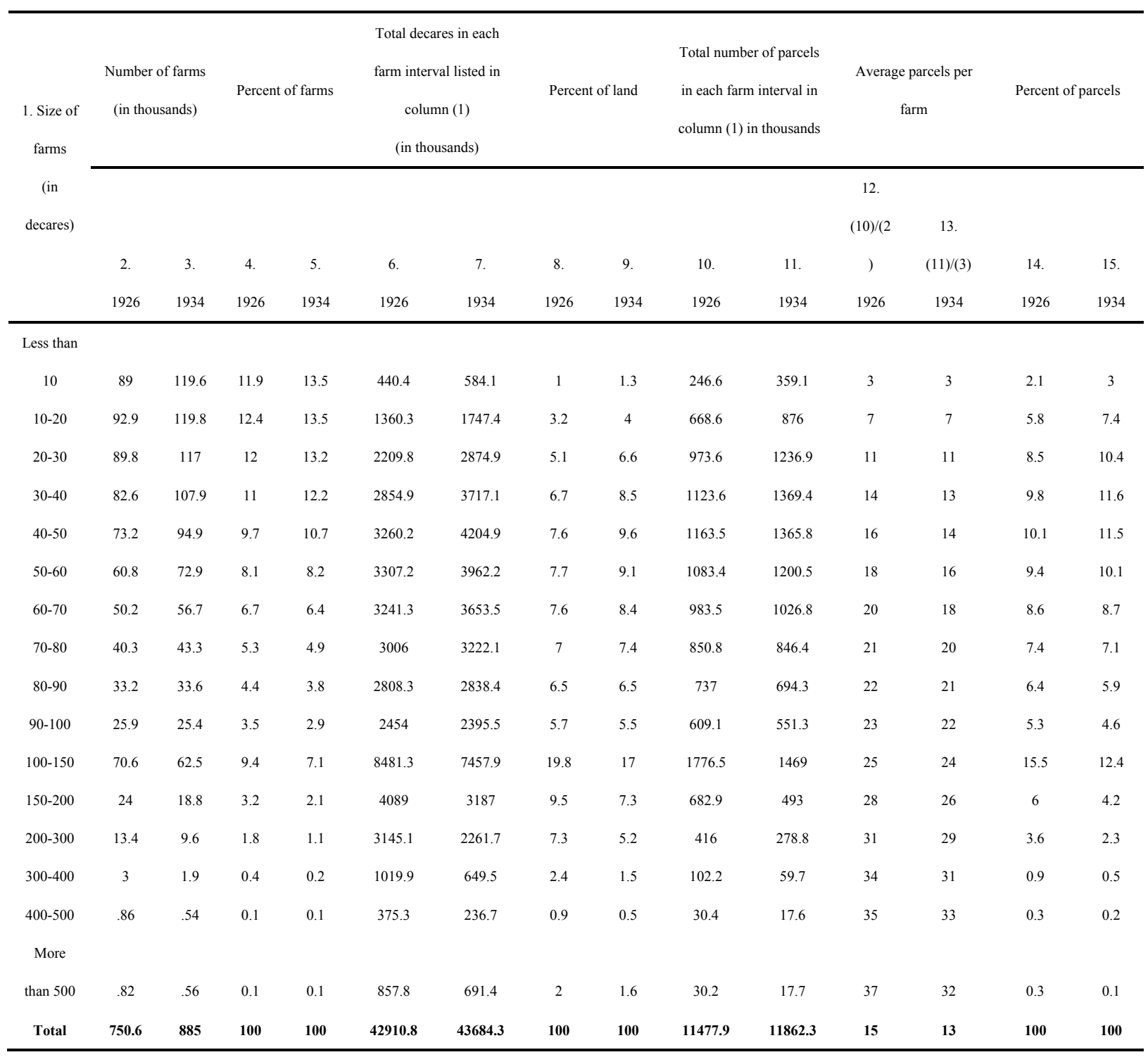

Source: Statistical Yearbook of the Kingdom of Bulgaria (1939, p. 182-183) and author's calculations 
Table 3. Percentage change in land distribution

\begin{tabular}{|c|c|c|c|c|c|c|c|c|c|}
\hline \multirow[t]{3}{*}{$\begin{array}{l}\text { 1. Size of farms } \\
\text { (in decares) }\end{array}$} & \multicolumn{3}{|c|}{$\begin{array}{c}\text { Percentage change in the } \\
\text { number of farms }\end{array}$} & \multicolumn{3}{|c|}{$\begin{array}{c}\text { Percentage change in the } \\
\text { number of parcels }\end{array}$} & \multicolumn{3}{|c|}{$\begin{array}{c}\text { Percentage change in } \\
\text { parcels per farm }\end{array}$} \\
\hline & 2. & 3. & 4. & 5. & 6. & 7. & 8. & 9. & 10. \\
\hline & 1897-1908 & 1908-1926 & 1926-1934 & 1897-1908 & 1908-1926 & 1926-1934 & $1897-1908$ & 1908-1926 & 1926-1934 \\
\hline Less than 10 & 0.14 & -0.70 & 0.34 & 0.11 & -0.55 & 0.46 & -0.05 & 0.50 & 0.00 \\
\hline $10-20$ & 0.23 & -0.29 & 0.29 & 0.11 & 0.10 & 0.31 & -0.04 & 0.40 & 0.00 \\
\hline $20-30$ & 0.15 & 0.04 & 0.30 & 0.09 & 0.37 & 0.27 & -0.08 & 0.38 & 0.00 \\
\hline $30-40$ & 0.14 & 0.21 & 0.31 & 0.13 & 0.43 & 0.22 & 0.04 & 0.17 & -0.07 \\
\hline $40-50$ & 0.15 & 0.27 & 0.30 & 0.20 & 0.42 & 0.17 & 0.03 & 0.14 & -0.13 \\
\hline $50-100$ & 0.17 & 0.21 & 0.10 & 0.27 & 0.32 & 0.01 & 0.09 & 0.09 & 0.01 \\
\hline $100-150$ & 0.22 & 0.04 & -0.11 & 0.36 & 0.11 & -0.17 & 0.13 & 0.04 & -0.04 \\
\hline $150-200$ & 0.21 & -0.10 & -0.22 & 0.35 & -0.04 & -0.28 & 0.13 & 0.04 & -0.07 \\
\hline $200-300$ & 0.16 & -0.23 & -0.28 & 0.29 & -0.18 & -0.33 & 0.09 & 0.07 & -0.06 \\
\hline $300-400$ & 0.16 & -0.40 & -0.36 & 0.31 & -0.38 & -0.42 & 0.15 & 0.03 & -0.09 \\
\hline $400-500$ & 0.09 & -0.56 & -0.37 & 0.20 & -0.53 & -0.42 & 0.11 & 0.03 & -0.06 \\
\hline More than 500 & 0.07 & -0.74 & -0.32 & 0.25 & -0.74 & -0.41 & 0.17 & 0.01 & -0.14 \\
\hline Overall change & 0.17 & -0.20 & 0.18 & 0.24 & 0.16 & 0.03 & 0.10 & 0.36 & -0.13 \\
\hline
\end{tabular}

Source: Author's calculations based on the Statistical Yearbook of the Kingdom of Bulgaria (1909, p. 183; 1915, p. $128-129 ; 1939$, p. 182-183)

Data illustrate the overwhelming prevalence of small independent landholders and the egalitarian distribution of land following the liberation from Ottoman rule in 1878. Since 1897 is the year of the first agricultural census in Bulgaria, it seems impossible to compare the 1897 distribution of farms to that of earlier periods. Therefore, one is tempted to assume that fragmentation emerged as a result of division of land - it is most often and closely associated with the disintegration of large estates after liberation from Ottoman rule followed by the national policies of egalitarian land distribution. However, the painstaking research of Draganova (2005) on the Danubian Province of Bulgaria demonstrates that land distribution in the 1870s was very similar to that in the first half of the $20^{\text {th }}$ century. Based on data from the Ottoman land registries for Bulgaria, Draganova reports that in this period the average number of parcels per farm ranged from 2 for farms less than 20 daa to 43 for farms greater than 2000 daa (p. 84-86, 93). The overall average number of parcels per farm was 11.4. The implication of Draganova's study is that high levels of fragmentation did exist before the post-liberation egalitarian policies and that those high levels had not emerged as a side effect or in relation to the resulting division of land; they had just persisted.

It is generally believed that subdivision of land into more parcels (due to, for example, partible inheritance) leads to fragmentation. Table 3 suggests that this is not true in the case of Bulgaria. Table 3 shows the percentage changes in the number of farms; the number of parcels; and the number of average parcels per farm between the periods 1897 to 1908 ; 1908 to 1926; and 1926 to 1934. It can be seen that in the years between 1897 and 1908, the increase in the number of parcels for farms less than 30 daa is accompanied with a decrease in the average number of parcels per farm and therefore decrease in the level of farm fragmentation. The table shows that during this period the number of farms increased faster than the number of parcels causing a decrease in fragmentation despite increase in the number of parcels. In the period 1908-1926, the number of parcels for farms larger than 150 daa decreases while the average number of parcels slightly increases. This can only be explained with a decrease in the number of farms larger than 150 daa, which is confirmed with the results in column two. In summary, more parcels by itself, need not imply more fragmentation. Indeed, if we had no fragmentation (all one parcel farms), and then split each farm in two and gave half away, we would still have no fragmentation and a lot more parcels. It can be inferred that division of land is not always accompanied by increase in the level of fragmentation; the two do not necessarily go hand in hand as is often assumed and it is important to differentiate between the issue of division of land and that of LF.

\subsection{Post-Communist Period}

In the 2005 Annual Agricultural Report of the MAFS (p. 3-4), fragmentation is measured as the ratio between the area of the agricultural land in each district in Bulgaria and the number of parcels in this district which provides the average parcel size. ${ }^{4}$ As we have seen, small average parcel size need not imply fragmentation; it 
could be the case that a farm is composed of just one small parcel (in which case the farm is consolidated) so it is necessary to consider the number of farms as well. Other annual reports and studies of the MAFS, such as Kabil (2003) and Kasabov \& Koritarova (2004) support their arguments for high levels of fragmentation with figures demonstrating the increase in the percentage of small farms and decrease in the size of parcels that are owned or rented. In other words, the main criterion for fragmentation is the division of agricultural land in Bulgaria into small farms or simply the prevalence of small land ownership.

Kopeva (2000) defines LF as the "multiplicity of non-contiguous plots within a single farm enterprise" and lists the following national figures as the average number of parcels per farm for the period 1997/1998: 2 for small, 3.08 for medium, 3.68 for large farms and 2.62 is the country average number of parcels per farm. Comparing these numbers to the figures before collectivization Kopeva emphasizes that "the ongoing land and structural reform has brought the Bulgarian agriculture to a situation similar to the existing pre -communist one, especially in the sense of land fragmentation." But as we have seen above and as is presented by Kopeva, the figures for the periods before collectivization are much higher, especially for medium and large farms, as well as for the country average. The figures of Kopeva for 1997/1998 demonstrate just the opposite: a significant decline in the level of fragmentation in the post-communist period.

The average estimates for 1998 provided by Sabates-Wheeler (2002) are 3 to 7 parcels per farm; those provided by Rembold (2003) are 4 to 5 parcels per farm. Risina \& Mladenova (2002) indicate that most farms are composed on average of four, mostly scattered parcels. In a survey of 1400 agricultural households from three different regions in Bulgaria, Noev et al. (2004) find that in 2003, farms in this sample were composed of 1 to 20 parcels of land. The figures of Thomas (2006) are even higher: small, medium, and large farms were composed of 5, 11, and 13 parcels on average. Kopeva (2001) estimates that, before subdivision between heirs in 2001, small, medium, and large farms in Bulgaria were composed of 3, 4, and 6 parcels on average, respectively. After subdivision between heirs, this average is expected to reach 5,11 , and 13 parcels for small, medium, and large farms, respectively.

Regardless of disparity in the estimates, these studies argue for considerable and worrying level of fragmentation in the present period. However, the so presented disparate levels of LF are much lower than the pre-1944 period and none of the studies indicate this decline. On the contrary, the present level is considered equivalently alarming. Moreover, worrying about the effects of partible inheritance, most expect future levels of LF reaching or exceeding those of the period before 1944. However, while partible inheritance does lead to subdivision of land, there is no significant evidence indicating that it leads to land fragmentation (see the comprehensive reviews of Bentley, 1987; McCloskey, 1975; Blarel et. al., 1992).

\section{Measuring the 2003 Level of Fragmentation}

\subsection{Data}

The source of data for this study is the nationally representative Bulgaria 2003 Multitopic Household Survey (MHS). Funded by the World Bank, the MHS was conducted in late 2003 by the National Statistical Institute (NSI) of Bulgaria. The survey sample is comprised of 3023 households from the 28 official districts in the country.

The agriculture module includes the characteristics necessary to measure LF with the Simmons, Simpson, or Januszewski indices: ownership of farm land, the number of parcels which composes each farm, and the size of the parcels. According to this module, 1736 of the 3023 households or 57.43 percent of the surveyed households owned farmland. The maximum reported number of parcels which compose a farm is seven. Furthermore, the first of all plots owned by a household is characterized as yard, which is the parcel adjacent to the home of the household, implying zero travel distance. 70.33 percent of all parcels are located in the place of residence, implying short travel distance.

Table 4 summarizes the characteristics of the 1736 farms and Table 5 summarizes the distribution of farm sizes in daa. As shown in Table 4, the average and median size of farms and parcels is relatively small, about 15 and 7.5 daa, respectively. Table 5 shows that about 50 percent of farm households own farms that are smaller than 5 daa. More than 78 percent of farms are small with a size of less than 20 daa - a size considered below the minimum to provide a livelihood. Undoubtedly, these numbers display a heavily left-skewed distribution of farm sizes and indicate that, generally, households own relatively small areas of farmland.

\subsection{Measuring Land Fragmentation with the Simmons Index}

LF will be measured using the Simmons Index (SI) which is an adaptation of the Herfindahl's Index of market concentration. It is formulated by Simmons (1964) as follows: 


\section{F.I. $($ Fragmentation Index $)=\sum \mathrm{a}^{2} / \mathrm{A}^{2}$}

The index can better be expressed as

$$
\mathrm{SI}=\sum_{\mathrm{i}} \mathrm{A}_{\mathrm{i}}^{2} / \mathrm{A}_{\mathrm{j}}^{2}
$$

$\mathrm{A}_{\mathrm{ij}}$ is the area of the $i^{\text {th }}$ parcel of the farm $j ; \mathrm{A}_{\mathrm{j}}=\sum_{\mathrm{i}} \mathrm{A}_{\mathrm{ij}}$ is the total farm size for farm $j$, where $j=1,2, \ldots, k$, and $i=1$, $2, \ldots, m$ and where $k$ stands for the number of farms in the data and $m$ represents the number of parcels belonging to farm $j$. The index $m$ varies between farms as the number of parcels is different between different farms. The index is calculated separately for each household and as the formula implies, it expresses the relationship between the number of parcels comprising a farm and the relative sizes of these parcels; also, the index is independent of total farm size. ${ }^{5}$ It is obvious that the SI takes into account three of the parameters mentioned in Section 2: the number of parcels, the size of parcels, and the total farm size. The formula implies that the values of the SI can range from zero to one: a value of one will indicate that the household owns a single plot of land, meaning complete land consolidation. A value close to zero, on the other hand, will indicate extreme levels of fragmentation since SI approaches zero as the number of parcels cultivated by each farm grows.

Table 6 summarizes the measurements for the level of farmland fragmentation in Bulgaria derived from the MHS data. For about 42 percent of the households, the SI takes the value of one, indicating that 42 percent of the farms are completely consolidated. Overall, for more than 70.5 percent of farms, the SI is above 0.7 , indicating relatively low levels of LF.

In Table 7, the most frequently observed value is one, which characterizes the farm holdings of approximately 42 percent of the households. Only about 27 percent of farms are made up of three or more (up to seven) parcels of land.

Table 4. Selected farm-related characteristics for the sample of 1736 households that own farmland in Bulgaria in 2003

\begin{tabular}{lll} 
Description & Households who own land & Percentage of the total sample \\
& & \\
\hline Number of households & 1736 & \\
Median farm size (decares) & 5.2 & \\
Mean farm size (decares) & 14.92 & 42.11 \\
Number of farms composed of one parcel & 731 & 30.65 \\
Number of farms composed of two parcels & 532 & 15.32 \\
Number of farms composed of three parcels & 266 & 6.68 \\
Number of farms composed of four parcels & 116 & 2.59 \\
Number of farms composed of five parcels & 45 & 1.15 \\
Number of farms composed of six parcels & 20 & 1.50 \\
Number of farms composed of seven parcels & 26 & \\
Median number of parcels per farm & 2 & \\
Mean number of parcels per farm & 2.065 & \\
Mean parcel size (decares) & 7.49 & \\
Median Value of the Simmons Index & 0.94 & \\
Mean Value of the Simmons Index & $\mathbf{0 . 8 2}$ & \\
Lower bound of the Simmons Index & $\mathbf{0 . 2 3}$ & \\
Upper bound of the Simmons Index & $\mathbf{1}$ & \\
\hline
\end{tabular}


Table 5. Distribution of farm size for the sample of 1736 households that own farmland in Bulgaria in 2003

\begin{tabular}{lll}
\hline Range of Farm Size (in decares) for the sample of 1736 & Number of Households & Percentage of Households \\
\hline FS $<=5$ & 865 & 49.83 \\
$5<$ FS $<=10$ & 210 & 12.1 \\
$10<$ FS $<=20$ & 282 & 16.24 \\
$20<$ FS $<=30$ & 145 & 8.35 \\
$30<$ FS $<=40$ & 100 & 5.76 \\
$40<$ FS $<=50$ & 36 & 2.07 \\
$50<$ FS $<=100$ & 79 & 4.55 \\
$100<$ FS $<=150$ & 10 & 0.58 \\
$150<$ FS $<=200$ & 2 & 0.12 \\
FS $>200$ & 7 & 0.4 \\
Median farm size $=5.2$ & & \\
Mean farm size $=14.92$ & & \\
\hline
\end{tabular}

Table 6. Fragmentation of farmland using the simmons index

\begin{tabular}{lcc}
\hline $\begin{array}{l}\text { Value or Range of the Simmons Index } \\
\text { for the sample of } 1736\end{array}$ & Number of Households & Percentage of Households \\
\hline $\mathrm{SI}=0$ & 0 & 0 \\
$0<\mathrm{SI}<=0.1$ & 0 & 0 \\
$0.1<\mathrm{SI}<=0.2$ & 0 & 0 \\
$0.2<\mathrm{SI}<=0.3$ & 23 & 1.32 \\
$0.3<\mathrm{SI}<=0.4$ & 72 & 4.15 \\
$0.4<\mathrm{SI}<=0.5$ & 138 & 7.95 \\
$0.5<\mathrm{SI}<=0.6$ & 159 & 9.16 \\
$0.6<\mathrm{SI}<=0.7$ & 120 & 6.91 \\
$0.7<\mathrm{SI}<=0.8$ & 134 & 7.72 \\
$0.8<\mathrm{SI}<=0.9$ & 151 & 8.7 \\
$0.9<\mathrm{SI}<1$ & 211 & 12.15 \\
SI $=1$ & 728 & 41.94 \\
Median Value of the SI $=0.94$ & & \\
Mean Value of the SI $=0.82$ & & \\
\hline
\end{tabular}

Table 7. Fragmentation of farmland using average number of parcels per farm

\begin{tabular}{ccc}
\hline Number of Parcels & Number of Households & Percentage of Households \\
\hline 1 & 731 & 42.11 \\
2 & 532 & 30.65 \\
3 & 266 & 15.32 \\
4 & 116 & 6.68 \\
5 & 45 & 2.59 \\
6 & 20 & 1.15 \\
7 & 26 & 1.50 \\
Median $=2$ & & \\
Mean $=2.065$ & & \\
\hline
\end{tabular}

The finding that the level of farm fragmentation in Bulgaria is relatively low is somewhat surprising and interesting given the earlier review of the literature on LF in the country. It is even more interesting given that LF is considered as a major issue of the 1991 land reform. The MHS data show that on average farms are composed of two plots of land, whereas, various previous studies estimate the average farm composition to be in the range of four to 11 plots. And overall, the estimates here are very close to the ignored 1997/1998 estimates of 
Kopeva (2000), discussed in section 3.2. The results point to a radical decline in the level of fragmentation following the post-communist transition and examining the precise causes for this decline would be an interesting future contribution to the study of LF. The overwhelming prevalence of undersized farms and small landownership is certainly supported by the MHS data. However, the issue of undersized farms should be treated as separate from the issue of fragmentation.

It is essential to mention two further points. First, not shown here are the results for the SI when households who own, but do not cultivate their lands, are excluded from the sample. There are 440 such households constituting 25.3 percent of the 1736 landholders. Since the majority of that subset owns either one or two parcels of land, the mean and median values of the SI decrease from 0.82 to 0.78 and from 0.94 to 0.85 , respectively. This indicates a slightly higher level of fragmentation for households who own and operate their lands. Second, also not shown here is that the historical pattern that fragmentation increases as farm size increases does not hold at present. In contrast, there is no specific pattern. Surprisingly, the biggest farms are also the least fragmented $(\mathrm{SI}=0.85)$, followed by the smallest farms $(\mathrm{SI}=0.83)$.

\section{Conclusion}

The nationally representative MHS data indicate that LF in Bulgaria is present, but its current level can be considered low. Moreover, there is a significant decline in the level of fragmentation in the post-communist period so that it is the lowest at least since 1870s. This is in contrast to the argument that restitution of land brought back the pre-1944 level of LF. Future research on the causes of this decline would prove useful in our understanding of the evolution of fragmentation. This study draws attention to an important issue in the literature: there must be achieved a consistency in the conceptualization and measurement of LF if we are to assess accurately the nature of fragmentation and its impacts on economic outcomes. Researchers and policy makers should distinguish clearly the issue of undersized farms from the issue of having numerous parcels per farm. The paper clearly shows that they do not go hand in hand as is often assumed. The prevalence of undersized farms may be a problem but policymakers should be sure to be clear about which problem they are addressing. This is necessary in order to target correctly the areas which require policy intervention.

\section{References}

Bentley, J. W. (1987). Economic and Ecological Approaches to Land Fragmentation: In Defense of a Much Maligned Phenomenon. Annual Review of Anthropology, 16, 31-67. http://dx.doi.org/10.1146/annurev.an.16.100187.000335

Berov, L. (1981). Ikonomicheskoto razvitie na Bulgaria ot Osvobozhdenieto do kraya na XIX v. [Economic Development of Bulgaria from Liberation to end of $19^{\text {th }}$ Century]. In D. Angelov and L. Berov (Eds.), Stopanska Istoriya na Bulgaria 681-1981[Economic History of Bulgaria 681-1981] (pp. 217-262). Sofia, Bulgaria: Durzhavno izdatelstvo nauka i izkustvo.

Blarel, B., Hazell, P., Place, F., \& Quiggin, J. (1992). The Economics of Farm Fragmentation: Evidence from Ghana and Rwanda. World Bank Economic Review, 6(2), 233-254. http://dx.doi.org/10.1093/wber/6.2.233

Bulgaria Ministry of Agriculture and Food Supply (MAFS). (2004). Annual Agricultural Report 2004. Section A, $1-277$.

Bulgaria Ministry of Agriculture and Food Supply (MAFS). (2005). Annual Agricultural Report 2005. Section A, $1-277$.

Bulgaria Ministry of Agriculture and Food Supply (MAFS). (2007). National Strategy Plan for Rural Development (2007-2013), 1-46.

Draganova, S. T. (2005). Selskoto naselenie na Dunavski vilaet [The Rural Population of the Danubian Province]. Sofia, Bulgaria: Avangard Prima.

Dräger, D., \& Jaksch, T. (2001). Bulgaria. In S. J. Goetz, T. Jaksch, \& R. Siebert (Eds.), Agricultural Transformation and Land Use in Central and Eastern Europe (pp. 177-195). Burlington: Ashgate.

Howe, K. S. (1998). Politics, equity, and efficiency: Objectives and outcomes in Bulgarian land reform. In S. K. Wegren (Ed.), Land Reform in the Former Soviet Union and Eastern Europe (pp. 208-223). New York: Routledge. http://dx.doi.org/10.4324/9780203448571

Hung, P. V., MacAulay, T. G., \& Marsh, S. P. (2007). The economics of land fragmentation in the north of Vietnam. Australian Journal of Agricultural and Resource Economics, 51(2), 195-211. 
Igbozurike, M. U. (1974). Land tenure, social relations and the analysis of special discontinuity. Area, 6(2), 132-136.

Januszewski, J. (1968). Index of Land Consolidation as a Criterion of the Degree of Concentration. Geographia Polonica, 14, 291-296.

Kabil, N. (2004). Land Consolidation and Land Policy. Presentation at the Ministry of Agriculture and Forestry's Workshop "Land Consolidation and Land Policy in Bulgaria" held on 1-4 July 2004 in Plovdiv, Bulgaria.

Kasabov, M., \& Koritarova, V. (2004). Bulgarian-Dutch Project for Land Consolidation. Presentation at the Ministry of Agriculture and Forestry's Workshop "Land Consolidation and Land Policy in Bulgaria" held on 1-4 July 2004 in Plovdiv, Bulgaria.

King, R. L., \& Burton, S. P. (1982). Land Fragmentation: Notes on a Fundamental Rural Spatial Problem. Progress in Human Geography, 6(4), 475-494.

Kopeva, D. (2000). Aspects of Land Consolidation in Bulgaria. FAO Comparative Study on Land Fragmentation in Four CEECs: Bulgaria, Czech Republic, Hungary and Romania. Sofia: Institute for Market Economics.

Kopeva, D. (2001). Land Markets in Bulgaria. Land Settlement and Cooperatives. Land Reform 2003/3 FAO Special Edition, 41-58.

Kopeva, D., \& Noev, N. (2001). Aspects of Land Consolidation after the Land Reform. In O. Ieda (Ed.), The New Structure of the Rural Economy of Post-communist Countries, (pp. 123-159). Sapporo, Japan: Hokkaido University.

McCloskey, D. N. (1975). The Persistence of English Common Fields. In W. N. Parker, \& E. L. Jones (Eds.), European peasants and their markets: papers in Agrarian economic history (pp. 73-119). Princeton: Princeton University Press.

Noev, N., Swinnen, J. F, M., \& Vranken, L. (2004). The Development of Land Rental Markets in Bulgaria and the Former Yugoslav Republic of Macedonia. Research Group on Food Policy, Transition, and Development Working Paper 2004/1. Leuven: Katholieke Universiteit Leuven.

Rembold, F. (2003). Land fragmentation and its impact in Central and Eastern European countries and the Commonwealth of Independent States. In Land Reform, Land Settlement and Cooperatives. Budapest: FAO Economic and Social Department.

Risina, M., \& Mladenova, M. (2002). Po vuprosa za komasatsiyata na zemedelska zemya u nas [Land Consolidation in Bulgaria]. Ikonomika i upravlenie na selskoto stopanstvo, 6, 13-19.

Sabates-Wheeler, R. (2002). Consolidation Initiatives after Land Reform: Responses to Multiple Dimensions of Land Fragmentation in Eastern European Agriculture. Journal of International Development, 14(7), 1005-1018. http://dx.doi.org/10.1002/jid.905

Simmons, A. J. (1964). An Index of Farm Structure, with a Nottinghamshire Example. East Midlands Geographer, 3, 255-261.

Statisticheski godishnik na Tsartsvo Bulgaria. (1909). [Statistical Yearbook of the Kingdom of Bulgaria 1909]. Sofia, Bulgaria: Durzhavna pechatnitsa.

Statisticheski godishnik na Tsartsvo Bulgaria. (1915). [Statistical Yearbook of the Kingdom of Bulgaria 1915]. Sofia, Bulgaria: Durzhavna pechatnitsa.

Statisticheski godishnik na Tsartsvo Bulgaria. (1939). [Statistical Yearbook of the Kingdom of Bulgaria 1939]. Sofia, Bulgaria: Durzhavna pechatnitsa.

Thomas, J. (2006). Property rights, land fragmentation and the emerging structure of agriculture in Central and Eastern European countries. The Electronic Journal of Agriculture and Development Economics, 3(2), 225-275.

Toshev, D. I. (1937). Razpredelenieto i komasatsiyata na zemite v Bulgaria [Land distribution and land consolidation in Bulgaria]. Sofia, Bulgaria: Ministerstvo na zemedelieto i durzhavnite imoti.

Van Dijk, T. (2003). Scenarios of Central European land fragmentation. Land Use Policy, 20(2), $149-158$. http://dx.doi.org/10.1016/S0264-8377(02)00082-0 
Van Dijk, T., \& Kopeva, D. (2006). Land banking and Central Europe: Future importance, current initiatives and Western European past experience. Land Use Policy, 23(3), $286-301$. http://dx.doi.org/10.1016/j.landusepol.2004.07.005

Vulchev, N. (1999). Agrarnata struktura na Bulgarskoto zemedelie [The agrarian structure of farming in Bulgaria]. Sofia, Bulgaria: Gorekspres.

\section{Notes}

Note 1. A farm refers to a tract of land owned by one single household and used to grow variety of agricultural crops such as cereals, vegetables, fruits, tobacco, and others. That tract of land could be composed of one or more than one separate plots of land. Land fragmentation refers to the situation where one single household owns a farm composed of more than one separate plots of land.

Note 2. See the Annual Reports of the MAFS since 2004; the Bulgaria Rural Development Programme (2007-2013) of the European Agricultural Fund for Rural Development; Kopeva (2000, 2001); Kopeva and Noev (2001); Noev et al. (2004); Rembold (2003); Sabates-Wheeler (2002); Thomas (2006); Van Dijk (2003), Van Dijk \& Kopeva (2006).

Note 3. See Bentley (1987) for a review of most of these indices.

Note 4. District refers to the territorial/administrative division of Bulgaria where there are 28 districts.

Note 5. To maintain the relative order of importance of each size of plot to the others within a farm's total acreage, the size of each plot is weighted by the method of squaring (Simmons 1964). 